\title{
Morphometrical Study of human neonatal cerebral cortex (Age of 28 day)
}

Bader, K. Hameed ${ }^{1}$; Ayad, H. Ibraheem ${ }^{1}$ and Sammira, A-H. Abdullah2

${ }^{1}$ Department of Anatomy, College of Veterinary Medicine, ${ }^{2}$ Department of Anatomy, College of

Medicine, Tikrit University, Iraq.

E-mail: al_hadi2002@yahoo.com

Received: 16/12/2014; Accepted: 27/1/2016

\section{Summary}

The character and timing of gyral and sulci development is one manifestation of the complex orchestration of human brain development. This work describes the morphometry and thickness measurement of human neonate cerebral cortex at age of 28 days. Four Brains samples were fixed in $10 \%$ neutral buffer formalin for $24 \mathrm{hrs}$. Slides from various brain regions were prepared and routine hamatoxylin and eosine staining procedure was applied using histological technique. The present results clarify that the brain mean measurement from the frontal to the occipital pole was $189.6 \mathrm{~mm}$, while the measurements of the frontal, parietal, temporal and occipital cortices were $4.06,3.84,3.48$ and $3.68 \mathrm{~mm}$, respectively.

Keywords: Brain cortex, Brain development, Gyrification, Newborn.

\section{Introduction}

Cerebral cortex is the most highly developed part of human brain, and it is the most recent structure in the history of brain evolution (1). The character and timing of gyral development is one of the manifestation and complex orchestration of human brain development. The ability to quantify these changes would not only allow for deeper understanding of cortical development, but also conceivably allow for pathology improved detection (2). The central nervous system (CNS) appears at the beginning of the third week of gestation as a slipper-shaped plate of thickened ectoderm, the neural plate, in the mid-dorsal region in front of the primitive node. Its lateral edges soon elevate to form the neural folds (3). The neuroontogenic process in humans begins at gestational age (GA), 2-3 week with the folding and fusion of ectoderm to form the neural tube (4). At week 4 of gestation, the rostral portion of the neural tube forms three vesicles that are destined to give rise to the forebrain, the mid brain, and the hind brain (5-8). In the developing brain, the cortical sulci formation is a complex process starting from 14 weeks of gestation and on ward. The cortical folding occurs early during brain development (9). During fetal development, neurons are created and migrate to form the various parts of the brain. As neurons migrate, they also differentiate, so they begin to specialize in response to chemical signals (10). The process of development occurs sequentially from the more primitive to the more sophisticated sections. The first fully develop areas of the brain are the brain stem and midbrain, they govern the bodily functions necessary for life, the autonomic functions. At birth, the lower region of the nervous system are very well developed, while the higher regions, the limbic system and cerebral cortex are still rather primitive (11). Among cerebral cortex development is the most anterior (frontal) part of the neural tube, the telencephalon, which gives rise to the cerebral hemispheres and cortex (12). Most of the actual information processing in the brain takes place in the cerebral cortex and is involved in many complex brain functions as it plays a key role in memory, attention, perceptual awareness, thought, language, and consciousness (13). The cerebral cortex is divided into gyri and sulci whose morphology is variable among individuals (14). This anatomical organization is partly related to the cortical functional organization, and it may reflect Pathological functioning as specific abnormalities in the gyral and sulcal pattern are observed in certain developmental and neuropsychiatric disorder.

The aim of the study was determined the morphometry of the human neonate cerebral cortex at day (28) after birth, and to measure the initial cerebral cortex parameters.

\section{Materials and Methods}

Four samples of age 28 days neonatal brain were obtained from Baghdad forensic hospital. A coronal incision, anterior and posterior 
separation was made through the skull, and the brain was carefully removed. The whole brain samples were fixed in $10 \%$ neutral buffer formalin for $48 \mathrm{hrs}$., the spacemen sample then fixed in $10 \%$ neutral buffer formalin for 24 hrs., the samples were washed with tap water for $2 \mathrm{hrs}$. to remove the excess formalin vapour and debris. Measurement of brain samples was made using electronic digital caliber to determine the cerebral cortex thickness. The brain samples length by the tape measurement from the pole of frontal lobe to the occipital pole, while the cerebral cortex measurement by the electronic digital caliber, to determine the cerebral cortex thickness (15). Specimens were then digitally photographed.

\section{Results and Discussion}

The brain is formed by two cerebral hemispheres indicated by the presence of longitudinal cerebral fissure (Fig. 1), which extended from pole of frontal lobe to the occipital pole. The frontal lobe is well recognized and indicated by the presence of inferior, middle and superior gyri (Fig. 2), each of which was tortuous and covered by the pia matter which pass into the shallow sulci.

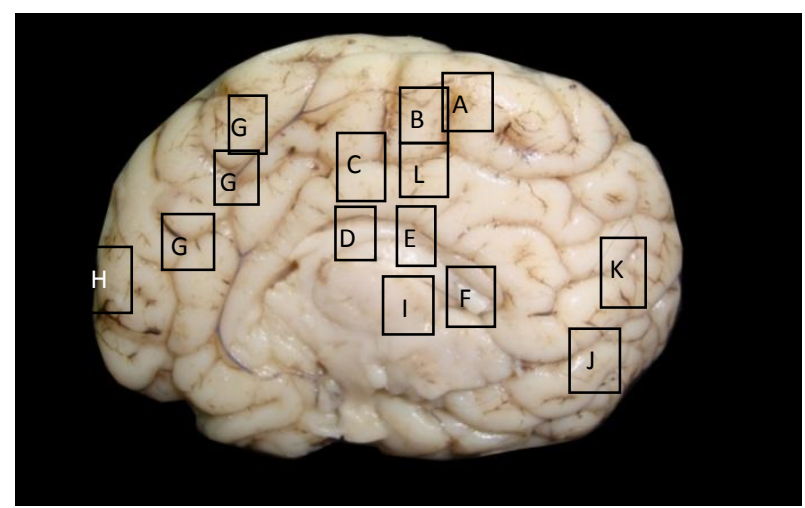

Figure, 1: Morphometry of cerebral cortex of age 28 day neonate indicate, A: Central sulcus, B: Paracentral lobule, C: Cingulate sulcus, D: Lateral ventricle, E: Corpus callosum, F: Fornix, G: Medial frontal gyrus, H: Frontal lobe, I: Thalamus, J: Calcarine sulcus, K: Parieto-occipital sulcus, L: Cingulate gyrus.

The parietal lobe was present superiolaterally and was also indicated by its gyri and deeper sulci, laterally extended to lateral fissure of temporal lobe. Superio-posteriorly, there was indication of the occipital lobe and its gyri and sulci. Laterally, the temporal lobe was present by the superior, middle and inferior gyri and superior and inferior sulci. The insular gyri detected and located in the floor of the longitudinal cerebral fissure of the posterior halve (Fig. 3 and 4).

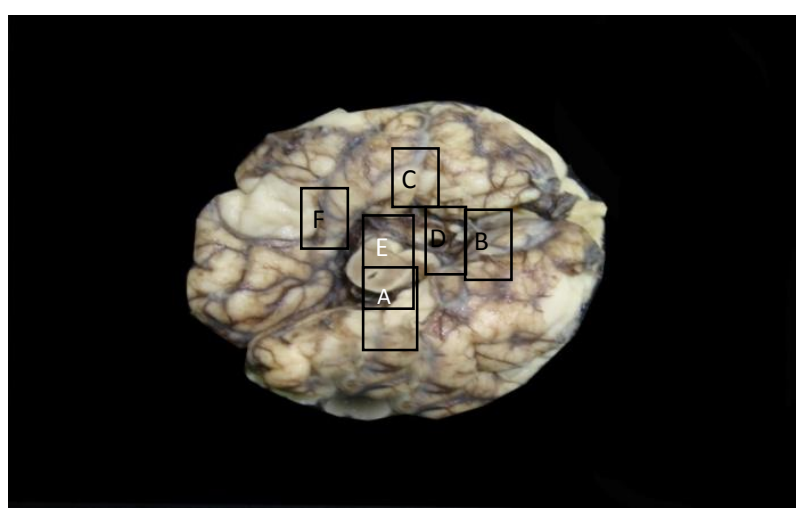

Figure, 2: Cerebral, A: Cerebral aqueduct, B: Optic nerve, C: Parahippocompus gyrus, D: Infundibulum, E: Mid brain (cut), F: Occipto- temporal sulcus.

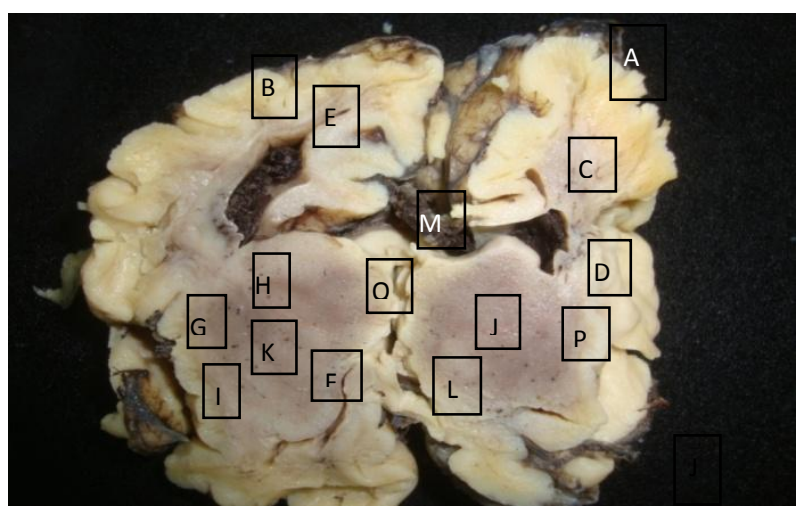

Figure, 3: Coronal section of Neonate brain demonstrating the following:- A: Pia matter, B: Gray matter, C: White matter, D: Insular cortex, E: Anterior horn of lateral ventricle, F: Posterior horn of lateral ventricle, G: Lentiform nucleus, H: Globus pallidus, K: Putamen), I: External capsule, L: Internal capsule, J: Thalamus, Q: Septum pellucidum, P: Claustrum, M: Coroid plexus.

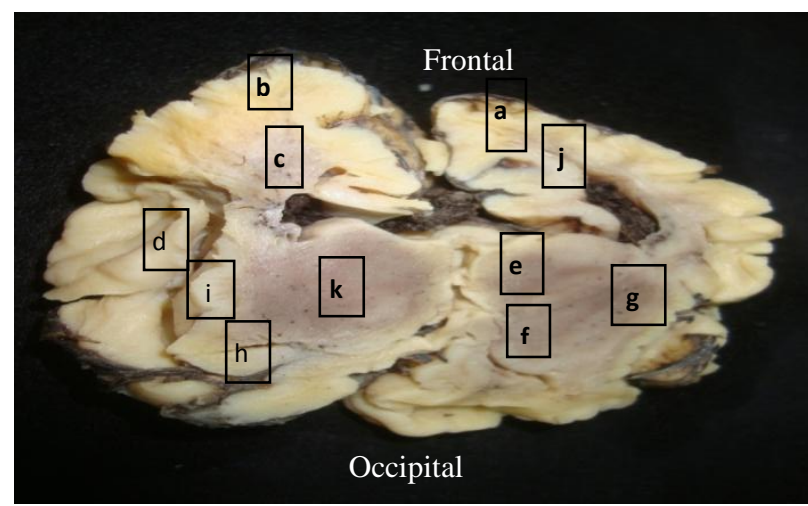

Figure, 4: Coronal section of Neonate brain showing, A: Pia matter, B: Gray matter, C: White matter, D: Insular cortex, E: Globus pallidus, F: Putamen, G: Lentiform nucleus, I: Claustrum, J: Anterior horn of lateral ventricle, $\mathrm{H}$ : Posterior horn of lateral ventricle, $\mathrm{K}$ : Thalamus. 
The morphometry and thickness of the various brain parts are shown in (Table, 1).

Table, 1: Morphometry (thickness) of four male brains of age 28 days.

\begin{tabular}{|c|c|c|c|c|c|}
\hline $\begin{array}{l}\text { Brain } \\
\text { Sample }\end{array}$ & $\begin{array}{l}\text { Measurement } \\
\text { of brain from } \\
\text { frontal to occipital } \\
\text { pole }(\mathrm{mm})\end{array}$ & $\begin{array}{l}\text { Frontal } \\
\text { cortex } \\
(\mathrm{mm})\end{array}$ & $\begin{array}{l}\text { Parietal } \\
\text { cortex } \\
(\mathrm{mm})\end{array}$ & $\begin{array}{l}\text { Temporal } \\
\text { cortex } \\
(\mathrm{mm})\end{array}$ & $\begin{array}{l}\text { Occipital } \\
\text { cortex } \\
(\mathrm{mm})\end{array}$ \\
\hline 1 & 174.50 & 3.80 & 3.70 & 2.85 & 3.00 \\
\hline 2 & 188.27 & 3.73 & 3.71 & 3.70 & 4.19 \\
\hline 3 & 180.44 & 4.03 & 3.71 & 3.72 & 4.04 \\
\hline 4 & 215.00 & 4.66 & 4.25 & 3.65 & 3.50 \\
\hline $\begin{array}{l}\text { Mean } \\
\pm \text { SE }\end{array}$ & $\begin{array}{r}189.553 \\
\pm 8.939\end{array}$ & $\begin{array}{c}4.055 \\
\pm 0.212\end{array}$ & $\begin{array}{c}3.843 \\
\pm 0.136\end{array}$ & $\begin{array}{c}3.480 \\
\pm 0.211\end{array}$ & $\begin{array}{c}3.683 \\
\pm 0.271\end{array}$ \\
\hline
\end{tabular}

This study was carried out for the first time. Early dissimilarities were outlined among newborns at birth (16). The cortical thickness measurement might point towards a structural abnormalities, and represent an early marker for the later appearance of functional disturbance and may be in part responsible for the lower measured in children born with intrauterine growth restriction (17). This study disagreed with (16) for the thickness of the cerebral cortex about 2-4 $\mathrm{mm}$. The study disagreed with Nieuwenhuys, Donkelaar, Nicholson; the thickness was about 2.3-2.8 $\mathrm{mm}$.

\section{References}

1. Jones, E. G. and Mendell, L. M. (1999). Assessing the Decade of the Brain. Sci. Am. Ass. Adv. Sci., 284(5415):739.

2. Pienaar, R.; Fischi, B.; Caviness, V.; Makris, N. (2008). A methodology for analyzing curvature in the developing brain from preterm to adult. Inter. J. Imaging Systems Technol., 18(1):42-68.

3. Sadler, T.W. and Longmans (2010). Medical embryology- Human- Textbook Lippincott Williams and Wilkins, Pp: 293-296.

4. Ladher, R. and Schoenwolf, G. C. (2005). Making a neural tube: neural tube induction and neurrulation In: Mahendra SR, Jacobson M (eds). Developmental Neurobiology4th edn. Kluwer Academic/Plenum Publishing: New York, Pp: 1-20.

5. Jessell, T. M.; Sanes, J. R. (2000). The decade of the developing brain. Curr Opin Neurobiol. 10:599-611. [PubMed].
6. Rash, B. G. (2006). Grove EA. Area and layer patterning in the developing cerebral cortex. Curr. Opin. Neurobiol., 16:25-34.

7. Rhinn, M.; Picker, A. and Brand, M. (2006). Global and local mechanisms of forebrain and midbrain patterning. Curr. Opin. Neurobiol., 16:5-12.

8. Stern, C. D. (2001). Initial patterning of the central nervous system: How many organizers. Nat. Rev. Neurosci., 2:92-98. [PubMed].

9. Als, H.; Butler, S.; Kosta, S. and McAnulty, G. (2005). The assessment of preterm infants behavior (APIB): Furthering the understanding and measurement of neurodevelopmental competence in preterm and full- term infants. Ment Retard Dev Disabil Res. Rev., 11:94-102.

10. Vidya, R.; Julia, S.; Piotr, A. H.; Kio, K.; James, C. D.; Francois, R.; James, B. and Orit, A. G. (2011). Colin Studholme Local tissue growth patterns underlying normal fetal human brain gyrification quantified in utero. J. Neurosci., 31(8):2878-2887.

11. Richa, T.; Nuzhat, H.; Ram, K. S. R.; Sona, S.; Savita, S.; Gyanendra, K. M.; Vinita, D.; Mandakini, P.; Chandra, M. P. and Rakesh, K. G. (2009):Correlation of diffusion tensor imaging with histology in the developing human frontal cerebrum. Dev. Neurosci. 31(6):487-496.

12. Upender, M. B. and Naegele, J. R. (1999). Activation of microglia during developmentally regulated cell death in the cerebral cortex. Dev. Neurosci., 21(6): 491-505.

13. Welker, W. (1990). Why does cerebral cortex fissure and folds a review of determinants of gyri and sulci. In: Jones, E and Peters, A. editors. Comparative structure and evolution of cerebral cortex. Part II. Vol.8B. New York: Plenum. Pp: 3-136.

14. LEE, G.L.H.T. (1968). Manual of histologic staining methods of armed forces institute of pathology.

15. Dubois, M.; Benders, C.; Borradori-Tolsa and Cachia, A. (2008). Primary cortical folding in the human newborn; an early marker of later functional development. Brain, 3:2028 -2041.

16. Jump, U. K.; Eric, R.; Schwartz, J. H. and Jessell, T. M. (2000). Principles of Neural 
Science Fourth Edition. USA. McGraw-Hill. Pp: 324.

17. Geva, R.; Eshel, R.; Leitner, Y.; Valevski, A. F. and Harel, S. (2006). Neuropsychological outcome of children with intrauterine growth restriction: A 9Year prospective study. Pediatrics. 118:91-100.

$$
\begin{aligned}
& \text { دراسة شكلية لقشرة الدماغ في الأطفال حديثي الولادة للإنسان (عمر } 28 \text { يوم) }
\end{aligned}
$$

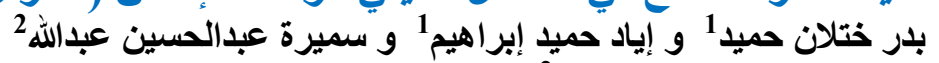

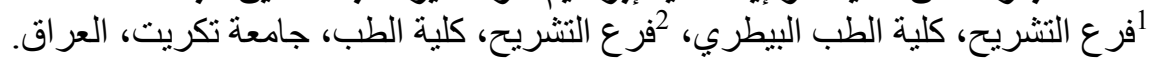

$$
\begin{aligned}
& \text { E-mail: al_hadi2002@yahoo.com } \\
& \text { الخلاصة }
\end{aligned}
$$

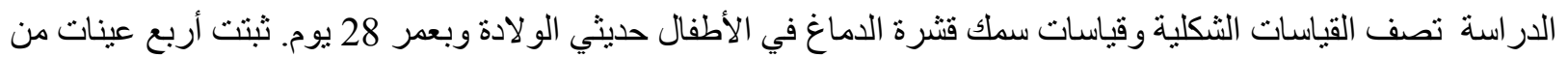

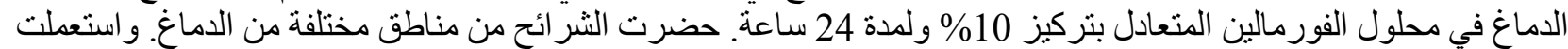

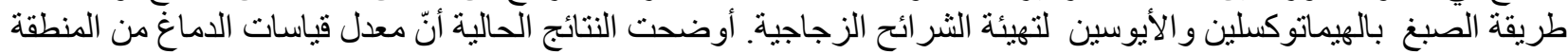

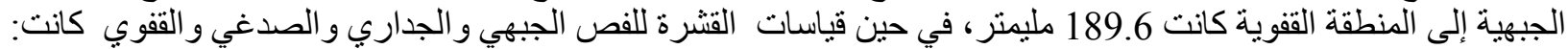

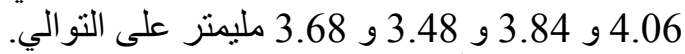
الكلمات المفتاحية: قشرة الدماغ، تطور الدماغ، تلاضفيف الدماغ، اطفال حليثي الولادة. 